\title{
Comparative analysis of the antioxidant capacity and lipid and protein oxidation of soy and oats beverages
}

\author{
Laura Moretto $^{1 \dagger} \mathbb{D}$, Federica Tonolo ${ }^{1 \dagger} \mathbb{D}$, Alessandra Folda ${ }^{1}$, Valeria Scalcon ${ }^{1} \mathbb{D}$, Alberto Bindoli ${ }^{2}$, Marco Bellamio ${ }^{3}$, \\ Emiliano Feller ${ }^{3}$ and Maria Pia Rigobello ${ }^{1 *}$ (D)
}

\begin{abstract}
Soy (Glycine max) and oats (Avena sativa) are plant sources used in milk-alternative beverages. However, protein and lipid constituents of these food matrices can undergo alterations during the storage. In this work, a commercial formulation of soy and oat-based beverages were comparatively evaluated. During the 12 months of shelf life and two following months, their phenolic content, antioxidant capacity, lipid peroxidation, protein carbonyl formation and protein breakdown were assessed. Total phenolic content and antioxidant capacity of soy and oat-based beverages were maintained during the entire period of 14 months. Both beverages did not show any increase in spontaneous lipid peroxidation beyond the basal level, however, due to the different content of unsaturated fats, when lipid peroxidation was stimulated, soy exhibited a major peroxidizability with respect to oat beverage. Oxidative alteration of proteins, estimated as carbonyl group formation, presented no increase with respect to the basal levels both in soy and oat beverages for all 14 months. Finally, soy proteins showed a gradual increase of proteolytic activity up until half of the shelf life, while oat did not show significant changes in protein fragmentation. In conclusion, both soy and oat beverages resulted oxidatively stable throughout their storage. We suggest that phytochemicals might guarantee the oxidative stability of the product, possibly in combination with antioxidant bioactive peptides, which already have well-known benefits on human health.
\end{abstract}

Keywords: Soy, Oats, Plant-based beverages, Oxidation, Antioxidants, Shelf life

\section{Introduction}

The consumption of non-dairy milk alternatives is steadily increasing and consumers show a noticeable interest in using plant-based beverages. These foods are milk substitutes suitable for vegetarian and vegan diets and for people suffering from lactose intolerance or milk proteins allergy (A. R. A. Silva et al. 2020). From a nutritional point of view, each plant-based beverage is endowed with a characteristic composition of carbohydrates, lipids, proteins and micronutrients. In addition, the various plant sources present unique

\footnotetext{
*Correspondence: mariapia.rigobello@unipd.it

${ }^{\dagger}$ Laura Moretto and Federica Tonolo contributed equally

'Department of Biomedical Sciences, University of Padova, via Ugo Bassi 58/ b, 35131 Padova, Italy

Full list of author information is available at the end of the article
}

bioactive compounds with potential health benefits. The most studied and popular beverages are derived from soy (Glycine max), due to its large use in Asian countries which dates back at least 2000 years. However, other milk alternatives, such as beverages based on oats (Avena sativa) are also requested (Sethi et al. 2016; A. R. A. Silva et al. 2020).

In the legume soy, the principal components are proteins $(40 \%)$, in particular the two major fractions $\beta$ conglycinin (7S) and glycinin (11S), together with other proteins such as protease inhibitor and lipoxygenase. Methionine is the least abundant amino acid in soybean proteins. Soybeans also contain lipids (about 20\%), mostly polyunsaturated fatty acids (about $59 \%$ of total fats), and carbohydrates (about 25-30\%). Furthermore, soybeans contain vitamins, minerals and bioactive

(c) The Author(s). 2021 Open Access This article is licensed under a Creative Commons Attribution 4.0 International License, which permits use, sharing, adaptation, distribution and reproduction in any medium or format, as long as you give

appropriate credit to the original author(s) and the source, provide a link to the Creative Commons licence, and indicate if changes were made. The images or other third party material in this article are included in the article's Creative Commons licence, unless indicated otherwise in a credit line to the material. If material is not included in the article's Creative Commons licence and your intended use is not permitted by statutory regulation or exceeds the permitted use, you will need to obtain permission directly from the copyright holder. To view a copy of this licence, visit http://creativecommons.org/licenses/by/4.0/ 
molecules. These include isoflavones (daidzein and genistein) and phenolic molecules with estrogenic activity, which are considered the major factor responsible for the health effects of soy products (Battistini et al. 2018; El-Shemy 2011).

Oats is a cereal and, consequently, carbohydrates constitute a large part of its composition, as it contains $60 \%$ starch. In oats, proteins (11-15\%) are higher in content with respect to other cereals and include globulins (avenalins) with fraction $12 \mathrm{~S}$ as their principal component, albumins, prolamins and glutelins (Ames et al. 2013; Gulvady et al. 2013). Globulins contain low amounts of cysteine and methionine but are rich in asparagine and glutamine (Shewry and Casey 1999). Moreover, oats contain lipids (7\%) such as polyunsaturated fatty acids (about 41\% of total fats) (Ames et al. 2013; Gulvady et al. 2013; Rasane et al. 2015; Singh et al. 2013). Oats also contain phenolic compounds including phenolic acids, flavonoids and precursors of phytoestrogens such as lignans. Notably, oat beverages contain avenanthramides, which are low molecular weight phenolic compounds found specifically in oats. They are amides of anthranilic and hydroxycinnamic acids which present different aromatic ring substituents (Gangopadhyay et al. 2015). They are endowed with different biological properties ranging from anti-irritant to anti-inflammatory and antioxidant effects (Gangopadhyay et al. 2015; Perrelli et al. 2018; Wise 2013). An important group of phytochemicals is represented by $\beta$-glucans as fibers. Other health beneficial compounds in oat are carotenoids and vitamins, vitamin $\mathrm{E}$ in particular.

Generally, the health effects of soy and oats are mainly attributed to bioactive compounds such as isoflavones and $\beta$-glucans, respectively. On the whole, the positive effects associated with the consumption of these two food matrices are the reduced risk of chronic diseases, maintenance of cardiovascular health and promotion of various digestive functions (Chang et al. 2013; Fuller et al. 2016; Korczak and Slavin 2013; Sethi et al. 2016; Yao et al. 2004).

In recent years, a great interest was addressed to antioxidants derived from natural sources and especially from plants. In this work, two plant-based beverages derived from soy and oats were taken into consideration and a comparative study of their antioxidant capacity during shelf life was carried out. In particular, their specific phenolic content and differences in composition of lipids and proteins, that may be subjected to oxidative damage during storage, were correlated.

\section{Materials and methods}

\section{Materials}

Trolox C, ABTS (2, 2'-azinobis(3-ethylbenzothiazoline 6-sulfonate)), gallic acid, 1,1-diphenyl-2-picrylhydrazyl (DPPH), IGEPAL CA-630, butylated hydroxytoluene
(BHT), dithiothreitol (DTT), hemin, cumene hydroperoxide (CHP), hydrochloric acid ( $\mathrm{HCl}), n$-butanol, $\mathrm{Na}_{2} \mathrm{CO}_{3}$, FolinCiocalteau reagent, phosphotungstic acid (PTA), potassium persulfate, sodium dodecyl sulfate (SDS), sodium hydroxide $(\mathrm{NaOH})$, sulfuric acid, thiobarbituric acid, Trizma base and urea were purchased from Merck-Fluka-Sigma-Aldrich (Darmstadt, Germany).

Ethanol, petroleum ether and trichloroacetic acid (TCA) were purchased from Carlo Erba Reagents S.r.l. (Cornaredo MI, Italy). Acetic acid glacial was purchased from AppliChem (Munich, Germany). Sodium tetraborate was purchased from VWR (Milano, Italy). 2,4- Dinitrophenylhydrazine (DNPH) was purchased from JT Baker (Thermo Fisher Scientific, Milano, Italy).

\section{Preparation of soy and oat-based beverages}

Soy and oat-based beverages were provided by Centrale del Latte di Vicenza as a commercial formulation. Beverages were obtained through grinding and soaking soybeans or rolled oat in water to obtain liquid extracts. Insoluble material was removed and ultra high temperature treatments were applied. Beverages derived from different production lots were analysed during the shelf life and for two additional months after the expiration date. The 12month-long shelf life of both beverages was established by the manufacturer, accounting for safety aspects and the sensory profile of the products.

\section{Composition of beverages and measurement of tocopherols and phenolic compounds}

Soy and oat-based beverages were analysed by an external facility (CHELAB, Resana, TV, Italy) for the quantification of bioactive molecules and composition as indicated in Table S1 and S2, respectively. In particular, proteins were evaluated by titrimetry, while total fats, dry substance, humidity, dietary fibers and ashes were quantified through gravimetric analysis. UNI EN 12822: 2014 was applied for determination of alpha-tocopherol. Total polyphenols were determined by solvent extraction and dilution of the samples at the right concentration. Then, extracted fractions were measured by HPLC/UVVis analysis against proper standard compounds.

\section{$\mathrm{pH}$ measure}

$\mathrm{pH}$ of each beverage of soy and oat was measured after 1:1 dilution with water $\left(\right.$ sensION ${ }^{\mathrm{m}}+\mathrm{PH} 31$, Hach, Iowa, USA), over the time of experimentation.

\section{Preparation of hydroalcoholic extracts}

The antioxidant activity of the beverage samples was measured by solvent extraction with a modified method described by Xu and Chang (2007) and Citta et al. (2017). Aliquots $(0.5 \mathrm{~mL})$ of beverages were added to $9.5 \mathrm{~mL}$ of $80 \%$ ethanol, mixed for $30 \mathrm{~min}$ in an orbital shaker and 
centrifuged at $16800 \mathrm{~g}$ for $20 \mathrm{~min}$ at $4{ }^{\circ} \mathrm{C}$. Then, the supernatants were filtered through Whatman Chr 1 to obtain hydroalcoholic extracts used for further analysis or maintained at $-20^{\circ} \mathrm{C}$.

\section{Total phenolic content (TPC)}

The total phenolic content was determined with the Folin-Ciocalteau reagent. Briefly, $1 \mathrm{~mL}$ of hydroalcoholic extract of beverages obtained as above was added to 1 $\mathrm{mL}$ of Folin-Ciocalteau reagent diluted 1:2 with water and incubated for $3 \mathrm{~min}$. Then, samples were treated with $2 \mathrm{~mL}$ of $10 \% \quad \mathrm{Na}_{2} \mathrm{CO}_{3}$ for $15 \mathrm{~min}$ at room temperature and then centrifuged at $6000 \mathrm{~g}$ for $5 \mathrm{~min}$. 1 $\mathrm{mL}$ of supernatant was estimated spectrophotometrically at $750 \mathrm{~nm}$ (Citta et al. 2017; Tonolo et al. 2019). Gallic acid was used as standard for the calibration curve. The results were expressed as milligrams of gallic acid equivalents per $100 \mathrm{~mL}$ of products (GAE).

\section{Antioxidant activity of hydroalcoholic extracts with ABTS method}

The antioxidant capacity of beverage extracts was analysed using ABTS scavenging test (Sochor et al. 2010; Tonolo et al. 2019). The method is based on the oxidation of ABTS to a free radical molecule $\left(\mathrm{ABTS}^{*+}\right)$. The latter was obtained after reacting $7 \mathrm{mM}$ ABTS with 2.46 $\mathrm{mM}$ potassium persulfate for $18 \mathrm{~h}$ in the dark at RT. Antioxidant activity was estimated by adding $0.02 \mathrm{~mL}$ of hydroalcoholic extract to $1 \mathrm{~mL}$ of $\mathrm{ABTS}^{\circ+}$ solution and the decrease of absorbance was measured at $734 \mathrm{~nm}$ after $20 \mathrm{~min}$. Trolox $\mathrm{C}$ was used as standard molecule by setting up a calibration curve and the obtained values were indicated as Trolox $\mathrm{C}$ equivalent antioxidant capacity (TEAC).

\section{Antioxidant activity of hydroalcoholic extracts with DPPH method}

The antioxidant activity of hydroalcoholic extracts was performed by the method described with some modifications (Tonolo et al. 2019 Wong et al. 2006). $0.8 \mathrm{~mL}$ of $0.1 \mathrm{mM}$ DPPH (1, 1-diphenyl-2-picrylhydrazyl) solution were added to $0.2 \mathrm{~mL}$ of hydroalcoholic extract. Decrease of absorbance was evaluated spectrophotometrically at $517 \mathrm{~nm}$ after $30 \mathrm{~min}$. Percentage of DPPH scavenging inhibition was calculated as:

$\% \mathrm{DPPH}$ scavenging $=\left(\mathrm{Abs}_{\text {control }}-\mathrm{Abs}_{\text {sample }}\right) /\left(\mathrm{Abs}_{\text {control }}\right) \times 100$

TBARS determination as an index of lipid peroxidation Lipid peroxidation was assessed following the formation of thiobarbituric acid-reactive substances (TBARS) (Citta et al. 2017). Aliquots of soy or oat-based beverages were treated with $3.9 \mathrm{~mL}$ of $0.1 \mathrm{~N}$ sulfuric acid and $0.5 \mathrm{~mL}$ of
$10 \%$ phosphotungstic acid (PTA) for $10 \mathrm{~min}$ at RT. Then, samples were centrifuged at $4000 \mathrm{~g}$ for $10 \mathrm{~min}$ and pellets were treated again with $2 \mathrm{~mL}$ of $0.1 \mathrm{~N} \mathrm{H}_{2} \mathrm{SO}_{4}$ and $0.3 \mathrm{~mL}$ of $10 \% \mathrm{PTA}$, following the same procedure. The dry pellets were dissolved in an aqueous solution (final volume of $4 \mathrm{~mL}$ ) in the presence of $0.25 \%$ IGEPAL, $0.01 \%$ BHT and $0.17 \%$ thiobarbituric acid. Samples were incubated for $60 \mathrm{~min}$ at $95^{\circ} \mathrm{C}$ and then cooled on ice for $15 \mathrm{~min}$. After centrifugation ( $4000 \mathrm{~g}$ for $10 \mathrm{~min}$ ), $3 \mathrm{~mL}$ of $\mathrm{n}$-butanol were added to the supernatant and vigorously mixed. Samples were centrifuged at $4000 \mathrm{~g}$ for $15 \mathrm{~min}$ and the fluorescence of the upper phase was measured with a plate reader (TECAN Infinite ${ }^{\bullet}$ M200 PRO, Männedorf, Switzerland) at $530 \mathrm{~nm}\left(\lambda_{\mathrm{Ex}}\right)$ and $540 \mathrm{~nm}\left(\lambda_{\mathrm{Em}}\right)$. Calibration curve for soy and oat beverages was set up with 1,1,3,3-tetrahydroxypropane standard solution and the results were expressed as nmol MDA equivalents/mL of product. When indicated, beverage samples were treated with $12 \mathrm{mM}$ cumene hydroperoxide (CHP) and $24 \mu \mathrm{M}$ hemin for $30 \mathrm{~min}$ at RT, and then processed as described.

\section{Proteolytic activity}

The proteolytic activity of samples was estimated utilizing ortho-phtalaldehyde (OPA) which is able to bind the amino group of proteins (Church et al. 1983). The light yellow "OPA reagent" is formed by $0.1 \mathrm{M}$ sodium tetraborate, $0.1 \%$ sodium dodecyl sulphate, $5.76 \mathrm{mM}$ ortho-phtalaldehyde dissolved in ethanol, and $5.7 \mathrm{mM}$ dithiothreitol (DTT). Briefly, $1 \mathrm{~mL}$ of soy and oat beverage was treated with $2 \mathrm{~mL}$ of $1 \%$ cold trichloroacetic acid (TCA) and $1 \mathrm{~mL}$ of water. Samples were filtered through Whatman Chr 1 and then with $0.22 \mu \mathrm{m}$ filters (Sartorius, Gottinga, Germany). Finally, $0.15 \mathrm{~mL}$ of filtered sample was added to $3 \mathrm{~mL}$ of "OPA reagent" and the absorbance was measured at $340 \mathrm{~nm}$ after incubation at RT for $2 \mathrm{~min}$.

\section{Defatted soy and oat-based beverages}

Soy and oat-based beverages were defatted according to Tsopmo et al. (2010) with some modifications. Beverages were diluted with petroleum ether 1:3 and then, mixed overnight at $4{ }^{\circ} \mathrm{C}$. After 2 hours, solvent in the upper phase was removed and the lower phase lyophilized.

\section{Determination of carbonyl content}

Carbonyl content of soy and oat-based beverages was determined with modifications of the method described by Georgiou et al. (2018). Briefly, $5 \mathrm{mg}$ of lyophilized powder of the defatted beverages described above was dissolved in $0.1 \mathrm{~mL}$ of water. $5 \mathrm{M}$ urea $/ 50 \mathrm{mM} \mathrm{NaOH}$ $(0.5 \mathrm{~mL})$ was added to the samples and then, carbonyl groups were derivatized with $0.1 \mathrm{~mL}$ of $6 \mathrm{mM} \mathrm{DNPH}$ in $4 \mathrm{M} \mathrm{HCl}$ at $\mathrm{RT}$ for $30 \mathrm{~min}$ in the dark. A Master Mix solution was prepared $(0.32 \mathrm{M}$ Trizma-base and $0.32 \mathrm{M}$ acetic acid at $\mathrm{pH} 10)$ and was used $(0.575 \mathrm{~mL})$ to reach 
$\mathrm{pH}$ 7. Samples were transferred to glass tubes and 15 $\mathrm{mM}$ SDS (final concentration) was gently added. Then, samples $(1.25 \mathrm{~mL})$ were extracted three times with ethyl acetate/ petroleum ether solution (5:2), and centrifuged at $4000 \mathrm{~g}$ for $5 \mathrm{~min}$ at RT. The upper phase was removed and the bottom phase was extracted again and centrifuged at $15800 \mathrm{~g}$ for $5 \mathrm{~min}$. Protein content was estimated using the Bradford method (Bradford 1976). Supernatant absorbance was measured at $370 \mathrm{~nm}$ and results were expressed as nmoles/mg proteins of carbonyl groups.

\section{Statistical analysis}

Reported values are the mean \pm SD of at least four independent experiments. The analysis of variance was performed by multiple comparison test with Tukey-Kramer method. GraphPad InStat 3 was the software used for analysis. Only differences with $p<0.05$ were considered significant.

\section{Results and discussion}

In this work, we compared the antioxidant properties of soy and oat-based beverages during shelf life. To this purpose, different assays for determination of the antioxidant activity were performed and, in addition, lipid and protein oxidation were also estimated.

\section{Determination of total phenolic content}

The total phenolic content (TPC) was estimated with the Folin-Ciocalteau reagent and reported as milligrams of gallic acid equivalents (GAE) per $100 \mathrm{~mL}$ of sample (Fig. 1a). In both beverages, GAE values $(\mathrm{mg} / 100 \mathrm{~mL}$ product) were stable during shelf life and also for 2 months after the expiration date, showing remarkable oxidative stability. However, this test revealed differences in soy and oat beverages. In particular, oat-based beverages exhibited GAE values (about $15 \mathrm{mg} / 100 \mathrm{~mL}$ of product) lower than those observed in soy-based beverages, which are in the range of $25-30 \mathrm{mg} / 100 \mathrm{~mL}$ of product. This result reflects the different total phenolic content of the two beverages (Table S1). Oats contain phenolic acids and flavonoids (Gangopadhyay et al. 2015), and this cereal is specifically rich of avenanthramides showing antioxidant activities (Perrelli et al. 2018; Wise 2013). On the other hand, soy is plentiful of isoflavones, a group of flavonoids belonging to phytoestrogens. The major isoflavones present in soy are genistein and daidzein (50 and $40 \%$ of total isoflavones), but glycitein is an important component as well (10\%) (El-Shemy 2011). The different classes of phenolic compounds reflect the differences in GAE values obtained with the two matrices. However, both beverages showed stability in total phenolic content during the observed period and no loss of phenolic content was noted even after the expiration date. In soy beverages, the obtained trend was in accordance with what previously observed in fermented soy products, analysed during 50 days of shelf life (Tonolo et al. 2019).

\section{Antioxidant capacity of hydroalcoholic extracts with ABTS and DPPH methods}

By using the ABTS radical scavenging activity test, other differences between the two food matrices emerged (Fig. 1b). TEAC ( $\mu \mathrm{M}$ Trolox equivalent $/ \mathrm{mL}$ product) values obtained in soy beverages $(300 \mu \mathrm{M}$ TEAC) were three times higher with respect to the values observed in oat beverages (about $100 \mu \mathrm{M}$ TEAC), indicating a minor antioxidant capacity of the latter. However, both oat and soy beverage values were stable during shelf life and after the expiration date. Furthermore, in soy samples, from the fourth month of shelf life, a moderate increase of antioxidant capacity was observed with respect to the first 2 months, probably due to a slightly increased availability of antioxidant molecules in these phases of shelf life. In fact, this result correlates with the slight increase of total phenolic content in soy beverages at the end of shelf life, as previously shown (Fig. 1a). In addition, to confirm our data, DPPH scavenging test was utilized for measuring the antioxidant activity in hydroalcoholic extracts of the two beverages, as depicted in Fig. 1c. In soy beverage the obtained trend reflected what was found by the TPC and ABTS assays, with an increase occurring in the last months while in oat the antioxidant capacity was maintained rather constant or slightly decreases (Fig. 1b and c). The DPPH assay did not show the marked differences between the two beverages observed with the ABTS method, although the trend is still the same. This discrepancy might be due to the different chemistry occurring in the various assays utilized for estimating the total non-enzymatic antioxidant capacity, as each free radical probe exhibits different reactions rates and mechanisms.

Plants are rich in phytochemicals such as vitamin E, lignans and phenolic compounds. The effects of these molecules include not only benefits to human health but also food oxidative stability. In oats, vitamin E, phenolic acids such as caffeic and ferulic acids, and avenanthramides are the principal antioxidant molecules. In the analysed oat samples para-coumaric acid and ferulic acid content did not show significant changes during the shelf life (Figure S1 and Table S4). Other compounds present in small quantities are flavonoids (Peterson 2001; Rasane et al. 2015). On the other hand, the principal components of soy that show antioxidant activity are isoflavones, including both glucoside forms as genistin, daidzin and glycitin and especially aglycones (genistein, daidzein and glycitein) (El-Shemy 2011). As reported in Table S3, the total amount of isoflavone content in our 
a

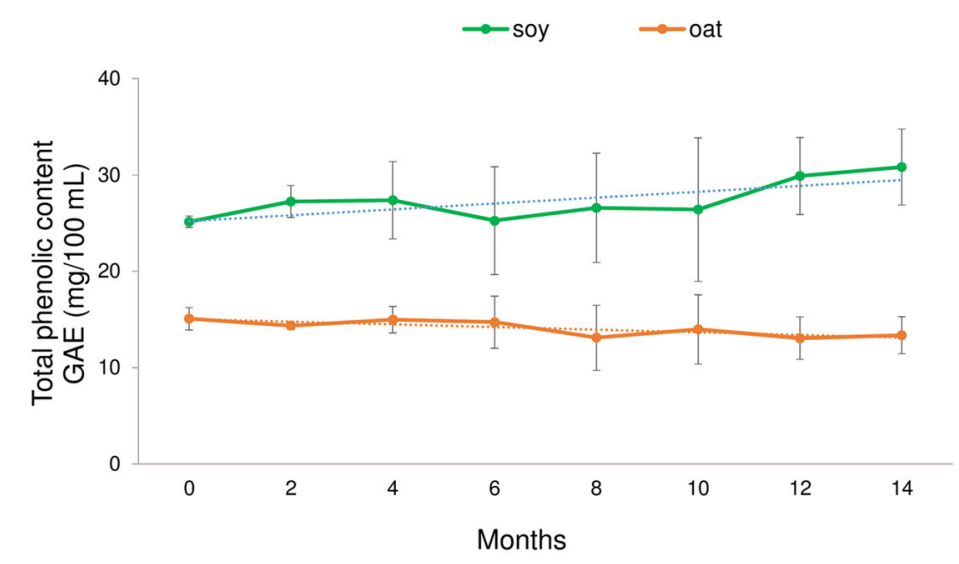

b



C

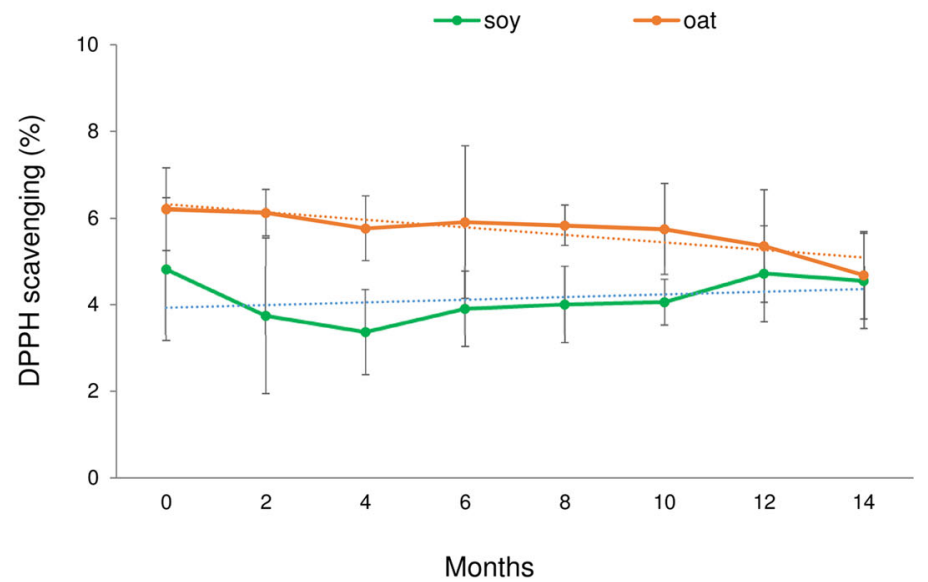

Fig. 1 Antioxidant capacity of soy and oat beverages during shelf life. Total phenolic content (a) was estimated with Folin-Ciocalteau reagent in hydroalcoholic extracts of the two beverages. Values are expressed as milligrams of gallic acid equivalents (GAE) per $100 \mathrm{~mL}$ of sample. In the ABTS assay (b), antioxidant capacity is expressed as $\mu \mathrm{M}$ Trolox equivalents $/ \mathrm{mL}$ product (TEAC). Trolox $C$ was used as standard molecule for the assay. In the DPPH assay (c), antioxidant capacity is expressed as percentage of DPPH scavenging capacity. ${ }^{*} p<0.05,{ }^{* *} p<0.01$ 
samples $(0,14$ months $)$ of soy beverages did not change significantly, although the aglycones decreased during the shelf life. In fact, as reported by M. B. R. Silva et al. 2019 , in soy-beverages the aglycone content is affected by the production and processing. Furthermore, as reported in Table S1, soy-based beverages contain a higher content of total tocopherols with respect to oat-based beverages.

\section{Lipid peroxidation in soy and oat beverages}

Lipid peroxidation of the two beverages, potentially occurring during shelf life, was evaluated with the thiobarbituric acid (TBA) test which estimates the products deriving from lipid peroxidation (TBARS). Tetraethoxy propane, the bis (diehyl acetal) derivative of malondialdehyde (MDA), was utilized as standard and results are reported as MDA equivalents (nmol MDA equivalents/ $\mathrm{mL}$ ). MDA, together with several other aldehydes, is one of the terminal products of unsaturated lipids oxidative degradation and a useful marker for quantifying the lipid peroxidation process (Yagi 1984). The results reported in Fig. 2 show the spontaneous lipid peroxidation for soy (Fig. 2a) and oat (Fig. 2b), while Fig. 2c (soy) and d (oat) indicate the extent of lipid peroxidation stimulated with inducers of oxidative stress such as the combination of cumene hydroperoxide (CHP) and hemin. TBA assay showed that soy and oat-based beverages do not increase spontaneous lipid peroxidation during 14 months of storage (Fig. 2a and b). Instead, a decline of peroxidizability was seen, particularly in the soy beverage. However, the obtained results highlighted differences between the two matrices both in spontaneous (Fig. 2a-b) and forced (Fig. 2c-d) lipid peroxidation. In spontaneous lipid peroxidation, soy-based beverages exhibited over time an average value of $7.2 \mathrm{nmol}$ MDA equivalents $/ \mathrm{mL}$ of product while oat beverages showed an approximately five times lower average value of $1.6 \mathrm{nmol} \mathrm{MDA}$ equivalents $/ \mathrm{mL}$ of product (Fig. 2a-b). After lipid peroxidation stimulation with $\mathrm{CHP} /$ hemin, differences between the two beverages were similar, but with values for soy and oat largely amplified. In fact, in soy beverages, average TBARS formation was estimated in the order of $500 \mathrm{nmol}$ MDA equivalents/ $\mathrm{mL}$ of product, therefore more than ten times higher with respect to the values observed in oat beverages (about 27 nmol MDA equivalents/mL of product) (Fig. 2c-d). In fact, total fats in soy were about double with respect to those present in oat beverages and the fatty acid composition of the two food matrices were different (Table S2). The extent of lipid peroxidation is essentially related to the amount of unsaturated fatty acids, while food oxidation depends on the type and concentration of endogenous antioxidants that are critical in controlling the oxidative stability of the product. In soy matrix, lipids are about $20 \%$ of the total composition. The major fraction is represented by polyunsaturated fatty acids $(63 \%)$ while monounsaturated fatty acids account for $21 \%$ and, therefore, the relatively high values of lipid peroxidation observed in soybased beverages are due to the relatively high concentration of this class of fats. In oats, similarly to other cereals, lipids are lower with respect to soy. The principal lipids

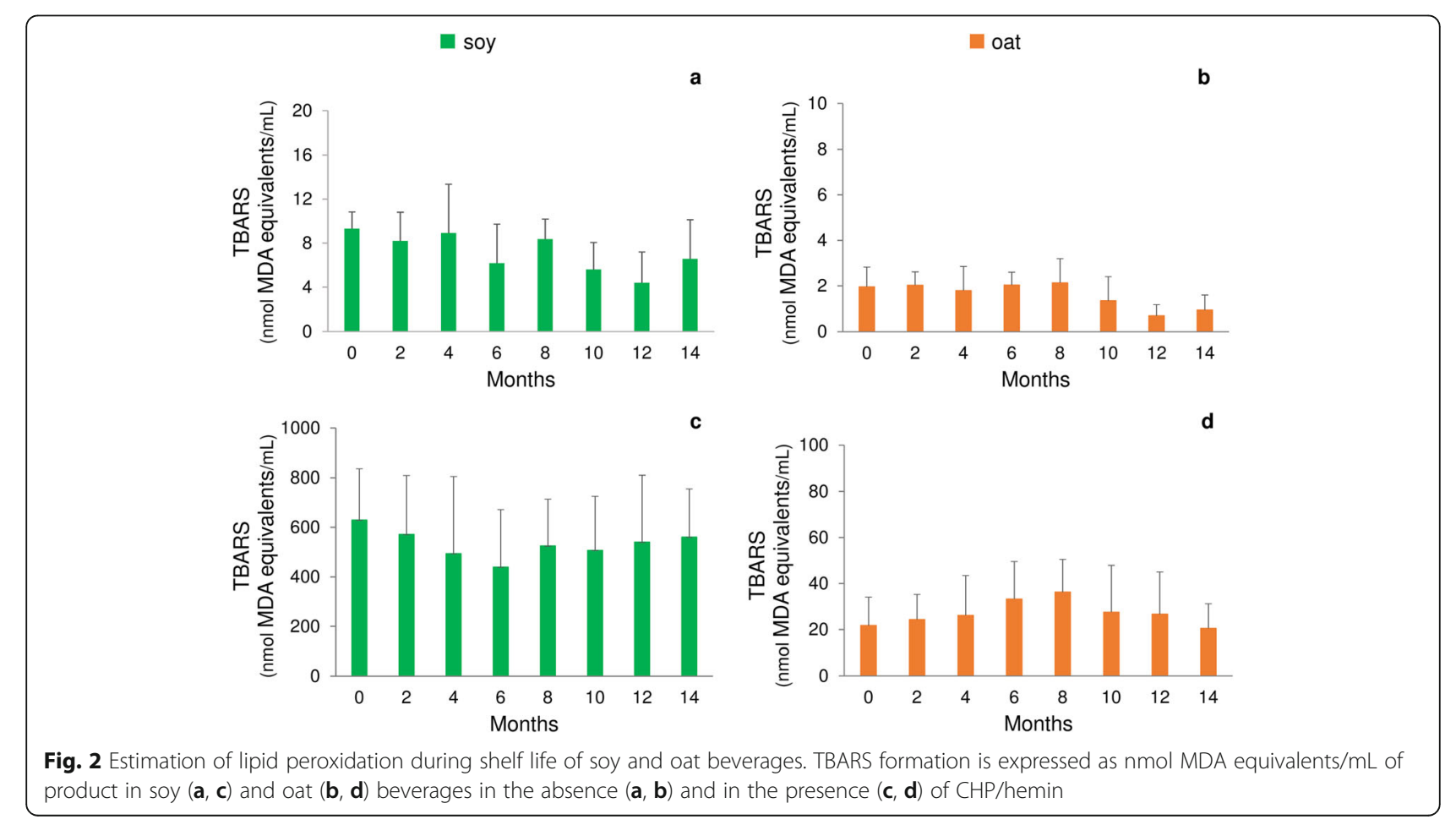


present in the oat matrix are localized in the endosperm and they consist of triacylglycerols, phospholipids and glycolipids. The fatty acids mainly present in oats are oleic acid, linoleic acid and palmitic acid (Rasane et al. 2015; Rosicka-Kaczmarek et al. 2015). However, the presence of specific endogenous antioxidants is a favourable factor for stability of oat-based beverages. Furthermore, in oat, a fiber fraction rich in proteins was also able to reduced lipid peroxidation (Lehtinen and Laakso 2000). Soy and oat contain enzymes such as lipase and lipoxygenase that can lead to deterioration of the product such as rancidity. However, heat processes can inactivate lipases and lipoxygenases by preventing their reaction with lipids. Heat treatments are therefore useful for decreasing rancidity and improve the shelf life (Ames et al. 2013; Decker et al. 2014). These observations confirm previously reported results showing that fatty acids did not change significantly during storage of oat-based beverages and also, linoleic acid shows no alterations (Zhang et al. 2007).

\section{Determination of carbonyl groups during shelf life}

Oxidative processes occurring during shelf life involve not only unsaturated lipids but also proteins. Furthermore, heat treatment utilized to avoid growth of microorganisms is a potential factor able to alter protein characteristics (Mäkinen et al. 2016). Therefore, determination of carbonyl groups, considered critical markers of protein oxidation, was performed using the specific reagent 2, 4-dinitrophenylhydrazine (DNPH). Most of the amino acid residues in proteins can form carbonyl groups either directly, after a reactive oxygen species attack, or indirectly, by the interaction of reactive aldehydes deriving from lipid peroxidation. The oxidation products of reducing sugars can also lead to the formation of protein carbonyls (Weber et al. 2015). To estimate carbonyl group formation, samples were defatted and, after reaction with DNPH, protein carbonyls were quantified by measuring the absorbance at $370 \mathrm{~nm}$. As shown in Fig. 3, during the shelf life no increase of carbonyl group concentration beyond the basal levels was observed in both soy and oat beverages. Therefore, the lack of increase of protein oxidation after the expiration date indicates a good oxidative stability. With soy protein, a slight decrease of carbonyl concentration took place during the first 6 months and subsequently the carbonyl values remained essentially constant for the further months (Fig. 3). As apparent in Table S2, the protein content was very different in the two matrices, about four times lower in oat with respect to soy. In addition, the amino acid composition of the major soy and oat proteins was evaluated using Uniprot database. We found that the amount of amino acid residues was different in the two food matrices, with tyrosine for example being more present in oat $12 \mathrm{~S}$ globulin with respect to soy glycinin G1 and $\beta$-conglycinin. Furthermore, cysteine and methionine are lower in soybean $\beta$-conglycinin with respect to $12 \mathrm{~S}$ oat globulin. These differences should be taken into account when considering protein oxidation and the consequent formation of carbonyl groups in the oat compared to soy-based product.

\section{Evaluation of $\mathrm{pH}$ changes of soy and oat beverages}

The degree of acidity of each beverage was measured every 2 months of shelf life during 14 months of analysis. The $\mathrm{pH}$ was different between the two samples, as depicted in Table S5. Oat-based beverages showed a $\mathrm{pH}$ in a range going from 6.32 to 6.02 , while soy-based beverages exhibited a range of $\mathrm{pH}$ from 7.68 to 7.41 (see Table S5). In soy beverages a decrease of respectively 0.16 and 0.23 units of $\mathrm{pH}$ was observed after 2 and 4 months of shelf life with respect to the initial estimation. However, starting from half shelf life time, the values were stable. This indicates a slight modification of the

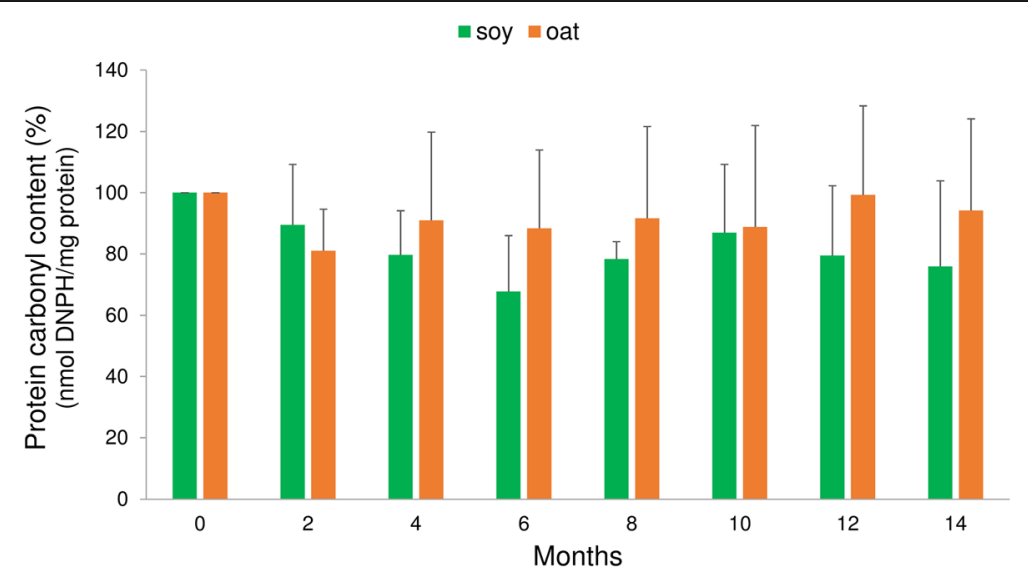

Fig. 3 Protein carbonyls during shelf life of soy and oat beverages. Protein oxidation was determined by estimation of carbonyl groups with the DNPH method. The values are reported as percentage of protein carbonyls content with respect to the initial month 
beverage occurring during storage and possibly due to proteolysis (Achouri et al. 2007). Similarly, in oat-based beverages, a decrement of $\mathrm{pH}$ occurred in the first months, but as early as the fourth month, values were essentially constant until the end of the storage time analysed. In both cases, the $\mathrm{pH}$ values observed during shelf life and after expiration date indicated a stability of the samples. These results led us to examine protein fragmentation during shelf life.

\section{Spontaneous proteolysis during shelf life}

Protein fragmentation was evaluated using the orthophtalaldehyde (OPA) assay. By this test, oat proteins resulted about ten times less sensitive to proteolytic attack compared to soy proteins (Fig. 4). Oat beverage showed very low absorbance values measured at $340 \mathrm{~nm}$ and significant changes in protein fragmentation were not found during the entire shelf life. In soy beverages a gradual increase of proteolytic activity until half of the shelf life was observed, reflecting the decrease in $\mathrm{pH}$ values during the initial period of shelf life and possibly the decrease of MDA and carbonyl group formation observed during the same time range (Figs. 2 and 3). This observation could be explained by the production of bioactive peptides due to spontaneous proteolysis.

\section{Conclusions}

During shelf life, soy and oat-based beverages showed significant differences in antioxidant properties and a different response to lipid and protein oxidation. Total phenolic content, estimated as GAE values, was about twice in soy with respect to oat beverages. Similarly, in soy beverage, antioxidant capacity, estimated as TEAC values with the ABTS test, is three times higher than oat beverage. In both types of beverages, the antioxidant activity was stable during the shelf life and for 2 months after expiration date. The antioxidant capacity of the

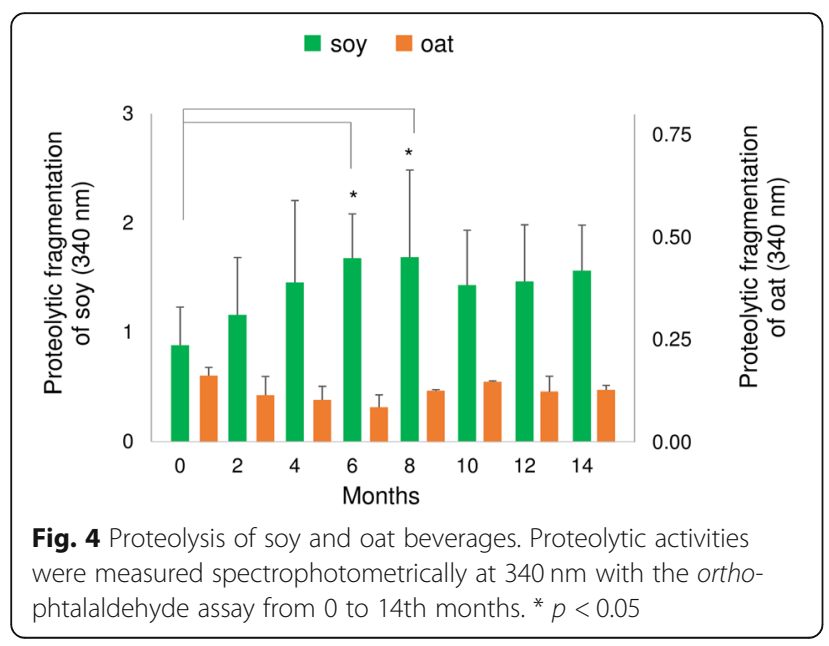

two matrices is different for each beverage and is due both to the amount and specific composition of endogenous antioxidants. Subsequently, the response of proteins and lipids toward oxidizing conditions was taken under consideration by different methodologies. Lipid peroxidation assayed as TBARS showed that soy and oat-based beverages did not increase peroxidative alterations during shelf life. However, significant differences between soy and oat were observed as soy lipids were more oxidized than lipids in oat matrix in both spontaneous and stimulated conditions. This is likely due to the higher unsaturated fatty acid content in soy with respect to oat. Hence, from the point of view of rancidity, during storage, oat beverages are potentially less prone to lipid peroxidation with respect to soy beverages. Finally, protein alterations were studied with regards to their fragmentation and oxidation. Oat proteins were not fragmented during the shelf life, while soy proteins showed an increased fragmentation up to the sixth month. This result suggests that antioxidant bioactive peptides may be released, exerting their properties of stabilizing the food matrix during the shelf life. In both soy and oat samples, carbonyl groups did not increase during shelf life and after expiration date, indicating a great stability of the products. Both beverages are able to retain their antioxidant capability during all shelf life of 12 months and did not undergo significant peroxidation of lipids and oxidation of proteins showing a remarkable stability. Differences in antioxidant capacity and lipid and protein oxidation were observed depending on the different composition of the two plant matrices.

\section{Supplementary Information}

The online version contains supplementary material available at https://doi. org/10.1186/s43014-020-00046-6.

Additional file 1: Table S1. Tocopherols, total polyphenols, vitamins and calcium estimation in soy and oat beverages. Table S2.

Composition of soy and oat beverages. Table S3. Isoflavone profile of soy-based beverages at 0 month and 14 month of shelf life. Table S4. Fenolic acid profile of oat-based beverages at 0 and 14 months of shelf life. Figure S1. HPLC analysis of phenolic acid profile of oat-based beverage. The evaluation of the alcoholic extract of oat-based beverage at 0 (a) and $14^{\text {th }}$ month (b) of shelf life was performed by HPLC analysis. (c) Superimposition of $\mathbf{a}$ and $\mathbf{b}$. Caffeic, para-coumaric and ferulic acids were used as standards (d). Para-coumaric and ferulic acids were added to the alcoholic extract of oat-based beverage at 0 and $14^{\text {th }}$ month, as internal standards (e and $\mathbf{f}$, respectively). Table S5. $\mathrm{pH}$ of soy and oat-based beverages.

\section{Abbreviations}

ABTS: 22'-azinobis(3-ethylbenzothiazoline 6-sulfonate); BHT: Butylated hydroxytoluene; CHP: Cumene hydroperoxide; DNPH: 2,4-

Dinitrophenylhydrazine; DPPH: 1,1-diphenyl-2-picrylhydrazyl; DTT: Dithiothreitol; GAE: Gallic acid equivalents; MDA: Malondialdehyde; OPA: Ortho-phthalaldehyde; PTA: Phosphotungstic acid; RT: Room temperature; TBARS: Thiobarbituric acid reactive substances; TPC: Total phenolic content; TEAC: Trolox C equivalent antioxidant capacity 


\section{Acknowledgements}

We wish to thank Dr. Davide Zabeo (Dept. of Chemistry and Molecular Biology, University of Gothenburg) for his critical reading of the manuscript and Dr. Lucia Biasutto (Institute of Neuroscience, CNR) and Dr. Sofia Parrasia (Dept of Biomedical Sciences, University of Padova) for their help in the HPLC analysis.

\section{Authors' contributions}

Moretto L. and Tonolo F. planned and performed the experiments, analysed the data and drafted the manuscript. Folda A. and Scalcon V. helped to process the data. Bellamio M. and Feller E. took care of the production of the samples. Bindoli A. and Rigobello M.P. designed the experiments, wrote and reviewed the manuscript. All authors have read and approved the final manuscript.

\section{Funding}

This work was supported by the Regione del Veneto (Italy) with FSE project 2105-50-11-2018 entitled: "La ricerca di base a supporto dell'azienda: realizzazione di un functional food e di nuovi nutraceutici per il benessere del consumatore" and with POR Veneto FESR 2014-2020 Asse 1 Azione 1.1.4 Progetto 3S_4H "Cibo intelligente per un futuro sostenibile" Capofila Rete Innovativa per l'Ecosistema Salute e l'Alimentazione Smart.

\section{Availability of data and materials}

Please contact authors for data request.

\section{Competing interests}

The authors declare that they have no competing interests.

\section{Author details}

'Department of Biomedical Sciences, University of Padova, via Ugo Bassi 58/ b, 35131 Padova, Italy. ${ }^{2}$ Institute of Neuroscience (CNR), viale G. Colombo 3, 35131 Padova, Italy. ${ }^{3}$ Centrale del Latte di Vicenza s.p.a, via A. Faedo 60, 36100 Vicenza, Italy.

Received: 24 June 2020 Accepted: 2 December 2020

Published online: 04 January 2021

\section{References}

Achouri, A., Boye, J. I., \& Zamani, Y. (2007). Changes in soymilk quality as a function of composition and storage. Journal of Food Quality, 30(5), 731-744. https://doi.org/10.1111/j.1745-4557.2007.00153.x.

Ames, N., Rhymer, C., \& Storsley, J. (2013). Food oat quality throughout the value chain. In Oats nutrition and technology, (pp. 33-70). Hoboken: Wiley. https:// doi.org/10.1002/9781118354100.ch3.

Battistini, C., Gullón, B., Ichimura, E. S., Gomes, A. M. P., Ribeiro, E. P., Kunigk, L., ... Jurkiewicz, C. (2018). Development and characterization of an innovative synbiotic fermented beverage based on vegetable soybean. Brazilian Journal of Microbiology, 49(2), 303-309. https://doi.org/10.1016/..bjm.2017.08.006.

Bradford, M. M. (1976). A rapid and sensitive method for the quantitation of microgram quantities of protein utilizing the principle of protein-dye binding. Analytical Biochemistry, 72(1-2), 248-254. https://doi.org/10.1016/ 0003-2697(76)90527-3.

Chang, H.-C., Huang, C.-N., Yeh, D.-M., Wang, S.-J., Peng, C.-H., \& Wang, C.-J. (2013). Oat prevents obesity and abdominal fat distribution, and improves liver function in humans. Plant Foods for Human Nutrition, 68(1), 18-23. https://doi.org/10.1007/s11130-013-0336-2.

Church, F. C., Swaisgood, H. E., Porter, D. H., \& Catignani, G. L. (1983). Spectrophotometric assay using o-phthaldialdehyde for determination of proteolysis in milk and isolated milk proteins. Journal of Dairy Science, 66(6), 1219-1227. https://doi.org/10.3168/jds.S0022-0302(83)81926-2.

Citta, A., Folda, A., Scalcon, V., Scutari, G., Bindoli, A., Bellamio, M., ... Rigobello, M. P. (2017). Oxidative changes in lipids, proteins, and antioxidants in yogurt during the shelf life. Food Science \& Nutrition, 5(6), 1079-1087. https://doi.org/ 10.1002/fsn3.493.

Decker, E. A., Rose, D. J., \& Stewart, D. (2014). Processing of oats and the impact of processing operations on nutrition and health benefits. British Journal of Nutrition, 112(S2), S58-S64. https://doi.org/10.1017/S000711451400227X.

El-Shemy, H. (2011). Soybean and health. London: INTECH Open Access Publisher. https://doi.org/10.5772/1007.
Fuller, S., Beck, E., Salman, H., \& Tapsell, L. (2016). New horizons for the study of dietary fiber and health: a review. Plant Foods for Human Nutrition, 71(1), 112. https://doi.org/10.1007/s11130-016-0529-6.

Gangopadhyay, N., Hossain, M., Rai, D., \& Brunton, N. (2015). A review of extraction and analysis of bioactives in oat and barley and scope for use of novel food processing technologies. Molecules, 20(6), 10884-10909. https:// doi.org/10.3390/molecules200610884.

Georgiou, C. D., Zisimopoulos, D., Argyropoulou, V., Kalaitzopoulou, E., Salachas, G. , \& Grune, T. (2018). Protein and cell wall polysaccharide carbonyl determination by a neutral pH 2,4-dinitrophenylhydrazine-based photometric assay. Redox Biology, 17, 128-142. https://doi.org/10.1016/j.redox.2018.04.010.

Gulvady, A. A., Brown, R. C., \& Bell, J. A. (2013). Nutritional comparison of oats and other commonly consumed whole grains. In Oats nutrition and technology, (pp. 71-93). Hoboken: Wiley. https://doi.org/10.1002/9781118354100.ch4.

Korczak, R., \& Slavin, J. (2013). Effects of oats and B-Glucan on gut health. In Oats nutrition and technology, (pp. 299-309). Hoboken: Wiley. https://doi.org/10. 1002/9781118354100.ch14.

Lehtinen, P., \& Laakso, S. (2000). Inhibition of linoleic acid oxidation by interaction with a protein-rich oat fraction. Journal of Agricultural and Food Chemistry, 48(11), 5654-5657. https://doi.org/10.1021/jf000343g.

Mäkinen, O. E., Wanhalinna, V., Zannini, E., \& Arendt, E. K. (2016). Foods for special dietary needs: non-dairy plant-based milk substitutes and fermented dairytype products. Critical Reviews in Food Science and Nutrition, 56(3), 339-349. https://doi.org/10.1080/10408398.2012.761950.

Perrelli, A., Goitre, L., Salzano, A. M., Moglia, A., Scaloni, A., \& Retta, S. F. (2018). Biological activities, health benefits, and therapeutic properties of avenanthramides: from skin protection to prevention and treatment of cerebrovascular diseases. Oxidative Medicine and Cellular Longevity, 2018, 117. https://doi.org/10.1155/2018/6015351.

Peterson, D. M. (2001). Oat antioxidants. Journal of Cereal Science, 33(2), 115-129. https://doi.org/10.1006/jcrs.2000.0349.

Rasane, P., Jha, A., Sabikhi, L., Kumar, A., \& Unnikrishnan, V. S. (2015). Nutritional advantages of oats and opportunities for its processing as value added foods-a review. Journal of Food Science and Technology, 52(2), 662-675. https://doi.org/10.1007/s13197-013-1072-1.

Rosicka-Kaczmarek, J., Mi, K., \& Makowski, B. (2015). Composition and functional properties of lipid components from selected cereal grains. Research Signpost.

Sethi, S., Tyagi, S. K., \& Anurag, R. K. (2016). Plant-based milk alternatives an emerging segment of functional beverages: a review. Journal of Food Science and Technology, 53(9), 3408-3423. https://doi.org/10.1007/s13197-016-2328-3.

Shewry, P. R., \& Casey, R. (1999). Seed proteins. Dordrecht: Springer Netherlands. https://doi.org/10.1007/978-94-011-4431-5.

Silva, A. R. A., Silva, M. M. N., \& Ribeiro, B. D. (2020). Health issues and technological aspects of plant-based alternative milk. Food Research International, 131, 108972. https://doi.org/10.1016/j.foodres.2019.108972. Silva, M. B. R., Falcão, H. G., Kurozawa, L. E., Prudencio, S. H., de Camargo, A. C., Shahidi, F., \& Ida, E. I. (2019). Ultrasound- and hemicellulase-assisted extraction increase $\beta$-glucosidase activity, the content of isoflavone aglycones and antioxidant potential of soymilk. Journal of Food Bioactives, 6 140-147. https://doi.org/10.31665/JFB.2019.6191

Singh, R., De, S., \& Belkheir, A. (2013). Avena sativa (oat), a potential neutraceutical and therapeutic agent: an overview. Critical Reviews in Food Science and Nutrition, 53(2), 126-144. https://doi.org/10.1080/10408398.2010.526725.

Sochor, J., Ryvolova, M., Krystofova, O., Salas, P., Hubalek, J., Adam, V., ... Kizek, R. (2010). Fully automated spectrometric protocols for determination of antioxidant activity: advantages and disadvantages. Molecules, 15(12), 86188640. https://doi.org/10.3390/molecules15128618.

Tonolo, F., Moretto, L., Folda, A., Scalcon, V., Bindoli, A., Bellamio, M., ... Rigobello, M. P. (2019). Antioxidant properties of fermented soy during shelf life. Plant Foods for Human Nutrition, 74(3), 287-292. https://doi.org/10.1007/s11130019-00738-6.

Tsopmo, A., Cooper, A., \& Jodayree, S. (2010). Enzymatic hydrolysis of oat flour protein isolates to enhance antioxidative properties, (p. 8).

Weber, D., Davies, M. J., \& Grune, T. (2015). Determination of protein carbonyls in plasma, cell extracts, tissue homogenates, isolated proteins: focus on sample preparation and derivatization conditions. Redox Biology, 5, 367-380. https:// doi.org/10.1016/j.redox.2015.06.005.

Wise, M. L. (2013). Avenanthramides: chemistry and biosynthesis. In Oats nutrition and technology, (pp. 195-226). Hoboken: Wiley. https://doi.org/10.1002/ 9781118354100.ch8. 
Wong, S., Leong, L., \& Williamkoh, J. (2006). Antioxidant activities of aqueous extracts of selected plants. Food Chemistry, 99(4), 775-783. https://doi.org/10. 1016/j.foodchem.2005.07.058.

Xu, B. J., \& Chang, S. K. C. (2007). A comparative study on phenolic profiles and antioxidant activities of legumes as affected by extraction solvents. Journal of Food Science, 72(2), S159-S166. https://doi.org/10.1111/j.17503841.2006.00260.x.

Yagi, K. (1984). Assay for blood plasma or serum. Methods in Enzymology, 105, 328-331. https://doi.org/10.1016/s0076-6879(84)05042-4.

Yao, L. H., Jiang, Y. M., Shi, J., Tomás-Barberán, F. A., Datta, N., Singanusong, R., \& Chen, S. S. (2004). Flavonoids in food and their health benefits. Plant Foods for Human Nutrition, 59(3), 113-122. https://doi.org/10.1007/s11130-004-0049-7.

Zhang, H., Önning, G., Triantafyllou, A. Ö., \& Öste, R. (2007). Nutritional properties of oat-based beverages as affected by processing and storage. Journal of the Science of Food and Agriculture, 87(12), 2294-2301. https://doi.org/10.1002/jffa.2987.

\section{Publisher's Note}

Springer Nature remains neutral with regard to jurisdictional claims in published maps and institutional affiliations.

Ready to submit your research? Choose BMC and benefit from:

- fast, convenient online submission

- thorough peer review by experienced researchers in your field

- rapid publication on acceptance

- support for research data, including large and complex data types

- gold Open Access which fosters wider collaboration and increased citations

- maximum visibility for your research: over $100 \mathrm{M}$ website views per year

At BMC, research is always in progress.

Learn more biomedcentral.com/submissions 